\title{
The Effect of, Education on the Legal Aspects of Domestic Violence against Women through Social Networks, on the Awareness and Attitude of Nursing Students
}

\author{
Mojgan Khazaienejad ${ }^{1}$, Akram Peyman² $^{2}$, Jalal Tohidi Nafe ${ }^{3}$, Simin Esmaeilpour Zanjani ${ }^{4}$ \\ ${ }^{1}$ Master of Nursing, Department of Nursing, Tehran Medical Sciences, Islamic Azad University, Tehran, Iran. ${ }^{2}$ Faculty \\ of Nursing and Midwifery, Department of Midwifery, Tehran Medical Sciences, Islamic Azad University, Tehran, Iran. \\ ${ }^{3}$ Faculty of Law, Tehran North Branch, Islamic Azad University, Tehran, Iran. ${ }^{4}$ Faculty of Nursing and Midwifery, \\ Department of Nursing, Tehran Medical Sciences, Islamic Azad University, Tehran, Iran.
}

\section{ABSTRACT}

\section{BACKGROUND}

According to world statistics, majority of women is subjected to multiple instances of domestic violence in their lifetime. According to the results of some studies, awareness and attitude towards violence against women in different groups of society are different. Therefore, this issue should be studied in different groups, especially medical personnel. International law and national law should be studied. Nurses are the first link in the chain of communication for identifying and helping the victims of domestic violence. Educating this group is therefore the most crucial step in the prevention and reduction of instances of domestic violence against women. The present study examines the effect of, education on the legal aspects of domestic violence against women through social networks, on the awareness and attitude of nursing students.

\section{METHODS}

A pre-post intervention design was used. Nursing students $(n=110)$ attended to the research. Of these, 98 completed the pre-post researcher-made questionnaire. Data was analysed in SPSS- 25 at the significance level of $p=0.05$.

\section{RESULTS}

Using the Wilcoxon signed-rank test, all post intervention scores were significantly higher than pre intervention scores. Awareness scores increased from a pre-training mean of 47.45 to $59.53(\mathrm{z}=-8.418, \mathrm{p}<0.05)$ and attitude scores increased from 75.26 to $88.66(\mathrm{z}=-8.527, \mathrm{p}<0.05)$.

\section{CONCLUSIONS}

Training on the legal aspects of domestic violence against women effectively improved nursing students' awareness and attitude.

\section{KEY WORDS}

Domestic Violence, Law, Social Network, Students
Corresponding Author: Simin Esmaeilpour Zanjani, Tehran Medical Sciences, Islamic Azad University, Tehran, Iran.

E-mail: s_esmaeilpour@yahoo.com

DOI: $10.14260 /$ jemds/2019/622

Financial or Other Competing Interests: None.

How to Cite This Article:

Khazaienejad M, Peyman A, Nafe JT, et al. The effect of, education on the legal aspects of domestic violence against women through social networks, on the awareness and attitude of nursing students. J. Evolution Med. Dent. Sci. 2019;8(37):28652869, DOI: 10.14260/jemds/2019/622

Submission 14-06-2019, Peer Review 01-09-2019, Acceptance 07-09-2019, Published 16-09-2019. 


\section{BACKGROUND}

The family is one of the most important institutions of the human society and the first social institution. The effect of family on the development, balance and actualization of individuals and the society is undeniable. A phenomenon that has been of interest to sociologists, psychologists and health education researchers with regard to families is men's violence against women.(1) This violence includes all the behaviours that physically, psychologically and sexually harm the other person.

Despite the social, economic and cultural differences in place, violence occurs in all countries. (2) Violence against women has a prevalence of $13 \%$ to $46 \%$ in European countries. (3) In Iran, the prevalence of violence against women has been reported as $66 \%$.(4) Statistics have shown that, on average, women are eight times more exposed to violence than men.(2) As for the type of violence exhibited, sexual violence has the lowest frequency and verbal violence the highest. (5)

Structural factors such as age, gender, socioeconomic status and ethnicity have been recognized as factors predicting violence.(6) According to previous studies, rape and domestic violence adversely affect women's health more than diseases like breast cancer and accidents.(1) In fact, the poor socioeconomic status of women in most societies plus false religious/cultural beliefs, fear of the loss of reputation and occasionally the absence of laws has facilitated domestic violence against women.(7) To prevent and treat domestic violence against women, first, it has to be believed as a truth, and then clear laws protecting the victims should be legislated -laws whose practice is strongly and effectively guaranteed, on the one hand, and which are in harmony with the social norms, on the other.

The high and continually increasing levels of violence have made judicial courts in different countries incorporate this issue into their laws and consider punishment for those who commit violent acts. ${ }^{(8)}$ These laws have also become of interest in Iran. The existing laws are divided into two segments: Laws against social violence and laws against domestic violence.(9) Nonetheless, according to studies conducted by Aliverdinia et al., women's knowledge and attitude about domestic violence is different in diverse societies. ${ }^{(10)}$ This issue should therefore be assessed in different classes of the society and the current laws should be carefully learnt. The role of the health system (Composed of nurses, midwives, doctors, etc.) in the prevention and control of violence against women is to empower women in dealing with such problems. Moreover, providing life skills education to women and familiarizing them with factors underlying domestic violence and how to avoid the facilitation of violence with the assistance of nurses can contribute significantly to the control of violent behaviours and incidents.(11)

Fernandez et al. (2017) argued that universities are not only responsible for cultural and technical education, but also for social and civil education. They emphasized the need for violence screening training to students providing healthcare services and considered their presence in related clinical settings necessary for the integration of theoretical and practical knowledge.(12)

Despite the high prevalence of domestic violence in various countries, including Iran, very few studies have been conducted on this subject, and given recent findings in Canada showing the students' greater use of social media for learning scientific topics,(13) the present study was conducted to examine the effect of training on the legal aspects of domestic violence against women through social networks on the awareness and attitude of nursing students.

\section{METHODS}

A pre-post intervention design was used. Study was conducted between April and December 2018. The study population consisted of all of the undergraduate nursing students $(\mathrm{N}=363)$ of the School of Nursing, Tehran Islamic Azad University of Medical Sciences. Nursing students $(n=110)$ attended to the research. Of these, 98 completed the pre-post researcher-made questionnaire. The inclusion criteria were (No history of participation in similar studies and having access to the internet and a willingness to take part). Next, a social group was formed in Soroush and WhatsApp applications called "the Orange Frame" for nursing students to join and study under the supervision of experts familiar with this process. This group meant to provide education on the legal aspects of violence against women. At least four messages extracted from the Iranian constitutional law and international laws on women's rights in domestic violence and the prevention of violence were sent to the group members every day from Saturday to Wednesday for four weeks in text, video and audio formats, and by the end of each week, the members were asked to give their feedback on having viewed these messages by sending "I have viewed the messages". At the end of each week, on Thursday afternoons, experts answered the members' questions for two hours.

Data were collected using a researcher-made questionnaire with three parts towards the legal aspects of domestic violence against women.

\section{Part 1}

Demographic characteristics (Sex, Age, and Experience of DV and Married or Single).

\section{Part 2}

Awareness presented a series of questions (32) related to knowledge of domestic violence rights and international law, Iran's civil laws on violence, nurses' protective and preventive measures with responses on a true, false, do not know basis. Correct answers were awarded 2 points, 1 point for do not know and 0 for an incorrect answer. Three questions were reverse coded for scoring purposes (Items 9, 11, 12). The reliability for this scale was satisfactory with a Cronbach's alpha coefficient of 0.81 .

\section{Part 3}

Attitude explored attitude on violence and its different types, international law and Iran's Supportive Laws on Domestic Violence routine enquiry and nurses' protective and preventive measures. It contains 21 attitude expressions. This Likert -type scale as follows: 1 = strongly disagree, 2 =disagree, $3=$ neutral, $4=$ agree, 5 = strongly agree. Five items were reverse coded for scoring purposes (Items 1,2,3,4 and 11). A total score was calculated. The reliability for this scale was satisfactory with a Cronbach's alpha coefficient of 0.86 . 
(The reliability of this questionnaire was assessed using the test-retest method, and $10 \%$ of the eligible subjects completed the questionnaire, and then, after an interval of ten days, they recompleted the questionnaire, the analysis of the results confirmed the tool's reliability with a Cronbach's alpha correlation coefficient). The participants completed the questionnaire before and one month after their training. The data obtained from these questionnaires were entered into SPSS-25. The data on participants' demographic details were examined and described using descriptive statistics (Frequency, mean and standard deviation) and relevant charts, and the study hypotheses were examined using the Wilcoxon test at a significance level of $0 / 05$. Because according to the Kolmogorov-Smirnov test $(\mathrm{sig}=0.555)$ data distribution was not normal.

\section{RESULTS}

The present study was conducted in 2018 to determine the effect of training on the legal aspects of domestic violence against women on the awareness and attitude of nursing students $(n=110)$. Of this 98 pre-post survey responses were matched using the ID code. Missing data were left as missing in the analysis.

The majority of the 98 participants were female, single, undergraduate students aged 19 to 23 years (Table 1). A total of $88.8 \%$ of the participants had no personal experience of domestic violence, while $67 \%$ had witnessed various acts of violence by the father against the mother.

To describe and assess each of the study variables (The students' awareness and attitude), a number of questions were included in the questionnaire in different domains, and the desired variable was created by summing up the scores of the questions in each domain (Table 2). Before the training, the most correct answers to the awareness questions were in the domains of violence and its different types and Iran's civil laws on violence. Meanwhile, there were only a few correct answers to the questions related to awareness about international documents on violence and nurses' protective and preventive measures. The results showed an increase in the students' awareness in the noted dimensions after they received the training. Also, before the training, their attitude toward the violence items was favourable, while they had the lowest mean score of attitude in terms of nurses' protective and preventive measures. The training created a desirable change in attitudes.

According to Table 3, the nursing students' mean awareness score was 47.45 out of a possible 64 , (SD=8.52) in the pre-test. At post intervention, participants' mean level of awareness increased to 59.33 out of a possible 64, $(S D=3.40)$. There was a significant, improved difference between pre-post intervention scores $(Z=-8.418, p<0.05)$.

\begin{tabular}{|c|c|c|}
\hline $\begin{array}{c}\text { Demographic } \\
\text { Characteristics }\end{array}$ & Status & N \\
\hline \multirow{2}{*}{ Sex } & Male & 10.7 \\
\cline { 2 - 3 } & Female & 89.3 \\
\hline \multirow{2}{*}{ Age } & $\leq 19$ & 30.7 \\
\cline { 2 - 3 } & $19<$ and $<24$ & 66.4 \\
\cline { 2 - 3 } & $\leq 24$ & 95.7 \\
\hline \multirow{2}{*}{ Single/Married } & Single & 4.3 \\
\cline { 2 - 3 } & Married & 88.8 \\
\hline \multirow{2}{*}{ With /without violence experience } & Without violence experience \\
\cline { 2 - 3 } & With violence experience & 11.2 \\
\hline \multicolumn{2}{|c|}{ Table 1. Demographic Characteristics } \\
\hline
\end{tabular}

\begin{tabular}{|c|c|c|c|c|c|c|c|c|}
\hline$\frac{\sigma}{d}$ & 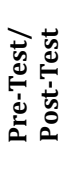 & 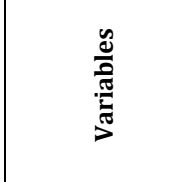 & z & $\stackrel{\Xi}{\Xi}$ & 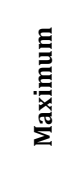 & 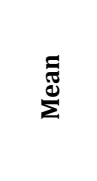 & 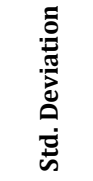 & 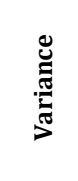 \\
\hline \multirow{12}{*}{ 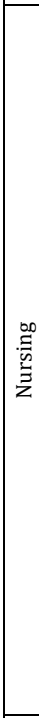 } & \multirow{6}{*}{ 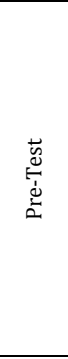 } & $\begin{array}{c}\text { The Context of } \\
\text { Violence }\end{array}$ & 98 & .00 & 6.00 & 5.7143 & .99483 & .990 \\
\hline & & \begin{tabular}{|c|} 
International \\
Documentation on \\
violence \\
\end{tabular} & 98 & .00 & 15.00 & 8.7347 & 4.26337 & 18.176 \\
\hline & & $\begin{array}{c}\text { The domain of } \\
\text { Iranian Civil Law }\end{array}$ & 98 & 10.00 & 30.00 & 23.7245 & 4.59444 & 21.109 \\
\hline & & $\begin{array}{c}\text { The Nursing } \\
\text { Support and } \\
\text { Preventive } \\
\text { Measures }\end{array}$ & 98 & .00 & 12.00 & 9.2857 & 2.11524 & 4.474 \\
\hline & & Awareness & 98 & 27.00 & 60.00 & 47.4592 & 8.52911 & 72.746 \\
\hline & & Attitude & 98 & 54.00 & 93.00 & 75.2653 & 6.72057 & 45.166 \\
\hline & \multirow{6}{*}{ 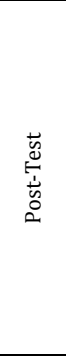 } & \begin{tabular}{|c|}
$\begin{array}{c}\text { The Context of } \\
\text { Violence }\end{array}$ \\
\end{tabular} & 98 & 4.00 & 6.00 & 5.9592 & .28424 & .081 \\
\hline & & \begin{tabular}{|c|} 
International \\
Documentation on \\
violence
\end{tabular} & 98 & 8.00 & 16.00 & 14.3367 & 1.37686 & 1.896 \\
\hline & & \begin{tabular}{|c|} 
The domain of \\
Iranian Civil Law
\end{tabular} & 98 & 18.00 & 30.00 & 27.7041 & 2.72147 & 7.406 \\
\hline & & $\begin{array}{c}\text { The Nursing } \\
\text { Support and } \\
\text { Preventive } \\
\text { Measures }\end{array}$ & 98 & 6.00 & 12.00 & 11.3367 & 1.19228 & 1.422 \\
\hline & & Awareness & 98 & 51.00 & 64.00 & 59.3367 & 3.40086 & 11.566 \\
\hline & & \begin{tabular}{|l|} 
Attitude \\
\end{tabular} & 98 & 66.00 & 101.00 & 88.6633 & 6.86684 & 47.153 \\
\hline \multicolumn{9}{|c|}{ Table 2. Descriptive Points of the Variables Studied } \\
\hline
\end{tabular}

\begin{tabular}{|c|c|c|c|c|c|c|c|}
\hline $\begin{array}{l}\frac{0}{0} \\
\frac{\pi}{3} \\
\frac{\pi}{3}\end{array}$ & $\sum_{\tilde{N}}^{n}$ & $z$ & 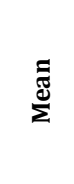 & 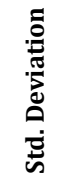 & 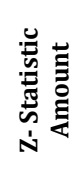 & 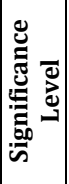 & 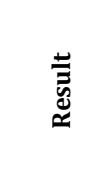 \\
\hline \multirow{2}{*}{ Knowledge } & Pre-test & 98 & $47 / 45$ & $8 / 52$ & \multirow{2}{*}{$-8 / 418$} & \multirow{2}{*}{0.00} & \multirow{2}{*}{ Significan } \\
\hline & Post-test & 98 & $59 / 33$ & $3 / 40$ & & & \\
\hline \multirow{2}{*}{ Attitude } & Pre-test & 98 & $75 / 26$ & $6 / 72$ & \multirow{2}{*}{$-8 / 527$} & \multirow{2}{*}{0.00} & \multirow{2}{*}{ Significant } \\
\hline & Post-test & 98 & $88 / 66$ & $6 / 86$ & & & \\
\hline \multicolumn{8}{|c|}{$\begin{array}{l}\text { Table 3. Comparing the Knowledge and Attitude of Nursing Students } \\
\text { with regard to Legal Aspects of Domestic Violence Before and After } \\
\text { Education }\end{array}$} \\
\hline
\end{tabular}

Also, the students' mean attitude score was 75.26 out of a possible 105 , $(\mathrm{SD}=6.72)$ in the pre-test. At post intervention, participants' mean level of attitude increased to 88.6 out of a possible 105 , $(S D=6.86)$. There was a significant, improved difference between pre-post intervention scores $(Z=-8.527$, $\mathrm{p}<0.05$ ).

\section{DISCUSSION}

Social networks were used to offer virtual education to the students in domains including the definition and types of violence, the Iranian Islamic Civil and Criminal Penal Codes on violence against women, the Security Enforcement Bill, the Convention on Elimination of all forms of Discrimination against Women (CEDAW) and nurses' role in performing protective and preventive measures for female victims. Comparing the pre-intervention and post-intervention results showed the positive effects of education on the students' awareness and attitude.

According to the results obtained by Duke et al. (2017) in Canada, providing students and professors with social media education and supporting their use are essential.(13) Given the influence of media in the contemporary times, the researchers decided to use this method of education in the present study. The anonymity and confidentiality of social media gave the 
students the opportunity to comfortably and continually ask their questions from the researchers, and this point can be considered one of the strengths of the study. Since most participants had only witnessed domestic violence and had no personal experience of it, they lacked the required motivation to read about the noted dimensions, but as training began, their eagerness to learn and ask and answer questions gradually grew.

One of the weaknesses of this study was participants' age range, i.e. 19-23 years, and also the small number of married participants compared to the singles. The small number of married subjects can be attributed to the increased age of marriage for women. A study by Pourakbaran et al. demonstrated the increased age of marriage in Iran.(14) Moreover, compared to the female students, male students were less willing to take part in this research. Consequently, the researchers were unable to examine the correlation between the demographic variables and the main variables, and further studies are recommended on this subject.

According to the results, most participants did not correctly answer the questions on awareness and attitude in the domains of international law and protective and preventive measures implemented by nurses with regard to domestic violence against women in the pre-test. For example, the answers to the awareness questions "Does the CEDAW emphasize gender equality?" and "Are nurses obliged to provide families with information about support sources and facilities in cases of violence?" were "Don't Know" and "No". The results thus indicated their lack of awareness in these domains. As already noted, most subjects in the present study were single and had no experience of domestic violence; as a result, they had little motivation for demanding their personal rights and their awareness was minimal. The students' lack of awareness on this subject seems to have been inevitable, given that Iran has not joined the CEDAW or passed the bill of women's security, which emphasizes education to medical staff and judiciary employees on these issues, and also due to the insufficient information exchange and training on these matters. Nevertheless, the United Nations' action of choosing an International Day for the Elimination of Violence against Women and promoting it in cyberspace and the students' use of social media have improved their awareness about the definition of violence and its types.

Regarding the students' attitude before and after the training, the highest mean score of favourable attitude belonged to domains including the concept of violence, such as "When angry, men can insult or batter women" and "Men can control women's income and assets", while before the training, the attitude with regard to domains including international documents and nurses' protective and preventive measures received the lowest mean scores. For example, the answers to attitude statements such as "Ending child marriage is a women's rights" and "Observing the signs of violence while taking the patient's medical history mandates the nurse to ask the patient who has hurt her and to put it in the records" were "No Comments" and "Disagree", but the subjects successfully developed the desired attitude after their training. The students' former unfavourable attitude can thus be attributed to their lack of awareness. The results obtained by Gorcan et al. in a study entitled "The effect of peer education in the fight for violence against women" confirm the present findings.(15)
The results of a study conducted by Fernandez et al. entitled "Intimate partner violence as a subject of study during the training of nurses and midwives in Catalonia (Spain)" showed that the students had lower sensitivity in their first encounter with intimate partner violence due to their false attitude, mentality and beliefs with regard to domestic violence as a normal occurrence. The professors therefore demanded more time for teaching violence-related materials to the students.(12) The results of other studies also indicated that education of the topic of violence against women on the increase of knowledge and attitude of nursing and midwifery students was positive. $(16,17)$

In a qualitative study conducted in Iran entitled "Female students' attitude toward violence against women", Aliverdinia et al. argued that the participants did not have a favourable attitude toward violence against women. The review of similar studies shows that extensive education is required to turn the common unfavourable attitudes into favourable attitudes that defend women's rights in Iran.(10)

\section{CONCLUSIONS}

The 2015-30 sustainable development goals, of which Iran is also a part, attaches the greatest importance to the efforts for establishing gender equality, the empowerment of women for reducing and ending all forms of violence, the improvement of social justice indices and the realization of women's security, and since discrimination and inequality are regarded as barriers to women's progress and ultimately prevent the eradication of poverty and the fight against diseases, developing appropriate laws to protect women's rights and educating people to observe their rights is a step towards the country's advancement. The present study showed that education is necessary for raising the awareness and improving the attitudes of men and women in domains such as the management of anger, conflict, communication problems, gender enmity and the current rights and laws, and given the vital role of healthcare staff, especially nurses, in preventing and reducing instances of violence against women through screening and education and by guiding the victims toward support and counselling centers, this group is recommended to receive further education on this issue.

\section{ACKNOWLEDGEMENT}

The present article is the result of a research thesis for a master's degree in Nursing, Community Health concentration, from Tehran Islamic Azad University of Medical Sciences, and supported by the university's research deputy. Hereby, we wish to express our gratitude to all the students who cooperated in the project.

\section{REFERENCES}

[1] Azghadi ZHB, Simbar M, Kermani M. Family violence against women: overview of theories, prevalence and the factors influencing it. Faculty of nursing and midwifery 
Quarterly of Shahid Beheshti University of Medical Sciences 2012;21(73):44-52. (Persian).

[2] Godarzi T, Rostami T, Moradian A. The impact of men's on family violence: focusing on violence against women. Quarterly Danesh- E- Entezami 2016;20:1-11 (Persian).

[3] United Nations (UN), "Report of the Secretary-General on Conflict-Related Sexual. Violence," S/2017/249, April 15, 2017, http://www.un.org/en/events/elimination-of.

[4] Tabatabai GM, Tabrizi MAR, Marjai SH. Studies on Domestic Violence against Women, Office of Public Affairs Ministry of Interior. Center of Women and Family Affairs, Presidency of the Islamic Republic of Iran, Tehran, Iran: 2005. (Persian).

[5] Torkashvand F, Rezaiian M, Sheikh Fatholahi M, et al. Surveying the frequency of family violence in women referring to health and treatment of Rafsanjan in 2013. Journal of Rafsanjan University of Medical Sciences 2014;12:695-708. (Persian).

[6] Latifi M, Taghdisi MH, Estebsari F, et al. Surveying violence against on wife and social factors inflicting on it in Tehrani families. Journal of Alborz University of Medical Scinces 2014;3(11):11-7. (Persian).

[7] Moazi M, Azami M, Shakeri M, et al. The association of wife abuse with mental health in women of Chahar Mahal Bakhtiari. Scietific Journal of Ilam University of Medical Sciences 2009;16(1):20-6. (Persian).

[8] Standish K. Understanding cultural violence and gender: honor killings, dowry murder, the Zina ordinance and blood-feuds. Journal of Gender Studies 2014;23(2):11124.

[9] The report of the Office of Cultural Studies of the Islamic Consultative Assembly Research Center entitled. "Code of Conduct Violence against Women in the Islamic Republic of Iran". 2010 (Persian).

[10] Aliverdinia A, Riahi ME, Esfandiari F. An explanation of girl students' attitude toward violence against women: experimental test of social learning theory. Biannual
Journal of Social Problems of Iran 2010;1(1):103-31. (Persian).

[11] Stanhope M, Lancaster J. Public health nursing: population-centered health care in the community. $9^{\text {th }}$ edn. Elsevier 2016.

[12] Gómez-Fernández MA, Goberna-Tricas J, Payà-Sánchez M. Intimate partner violence as a subject of study during the training of nurses and midwives in Catalonia (Spain): a qualitative study. Nurse Educ Pract 2017;27:13-21.

[13] Duke VJA, Anstey A, Carter S, et al. Social media in nurse education: utilization and E-professionalism. Nurse Educ Today 2017;57:8-13.

[14] Akbaran PE, Zadeh MM, Akbari F, et al. Surveying the reasons and factors for the increase in marriage age and its association with economic, social and cultural factors. The first national conference on the development and promotion of educational sciences, psychology, advice and education in Iran. Development and Promotion Of Fundamental Science and Technology Council, Tehran, Iran, 2014. (Persian). http://www.civilica.com/paoerPCCONF01-PCCONF01-123-HTML.

[15] Gürkan ÖC, Kömürcü N. The effect of a peer education program on combating violence against women: a randomized controlled study. Nurse Educ Today 2017;57:47-53.

[16] Baird KM, Saito AS, Eustace J, et al. Effectiveness of training to promote routine enquiry for domestic violence by midwives and nurses: a pre-post evaluation study. Women and Birth 2018;31(4):285-91.

[17] Sis Çelik A, Aydın A. The effect of a course on violence against women on the attitudes of student midwives and nurses towards domestic violence against women, their occupational roles in addressing violence, and their abilities to recognize the signs of violence. Perspectives in Psychiatric Care 2019;55(2):210-7. 